\title{
Early Interventions to Promote Pediatric Oral Health
}

\author{
Rehab Adel Mohamed Ali* \\ Clinical Instructor of Geriatric Nursing, Faculty of Nursing, Zigzag University, Egypt
}

*Corresponding author: Rehab Adel Mohamed Ali, Clinical Instructor of Geriatric Nursing, Faculty of Nursing, Zigzag University, Egypt

\section{Introduction}

It is well established that dental caries is the most prevalent and preventable chronic disease among children [1]. Preschool years are a critical period of development; poor oral health can create lifelong consequences for one's overall health outcomes. If oral health needs are not addressed earlier, it may negatively impact a child's ability to eat, sleep, learn or socialize, further damaging the child's psychological and social dimensions of well-being [1,2]. Another negative outcome is the need for dental surgery as it accounts for $31 \%$ of all surgeries among children under the age of 6 [3]. Caries in childhood is a predictor for adult oral health; this may affect other health conditions such as diabetes or cardiovascular disease over time [2]. Caries is a multifactorial chronic disease influenced by biological, lifestyle, and behavior factors [4]. Risk factors for early childhood caries include: bacteria transmission from mother to infant [5]; the social determinants of health [2]; parental knowledge [6], attitudes and behaviors towards oral health (e.g., diet, pacifier use, and daily tooth brushing); prolonged bottlefeeding practices [7], and cultural beliefs around primary or "milk teeth" $[8,9]$. Oral health is connected to socioeconomic status; those with higher income are more likely to access a dentist and have dental insurance coverage [10]. It is important to identify effective interventions targeting preschool children in order to collaborate with the Family Health Division, other Regional departments, and community partners to meet the emerging oral health needs of our community.

\section{Future Directions}

The recommendations made decades ago to promote early childhood oral health by establishing a dental home before the first birthday, and providing education and preventive interventions, are crucial components of effective care [11]. Now, as then, dental professionals play a pivotal role by assessing and monitoring the individualized risk of each pediatric patient and applying the latest evidence-based approaches to disease prevention and treatment
[12]. Effective care requires a constant review the literature, ongoing assessment of the rapidly evolving understanding of the oral microbiome and its effect on caries progression and implementing management protocols as early as possible. Beyond the clinic, however, it is equally important for dental teams to provide parents/caregivers with the knowledge and skills to make appropriate dietary and lifestyle choices for their children, while ensuring proper oral hygiene and regular dental visits. It is only through these combined efforts that oral disease can be prevented.

\section{Key Takeaways}

a) Establishing a dental home before a child's first birthday ensures a safe place for comprehensive care and allows clinicians to develop recommendations specific to that patient's individualized risk.

b) Assessing caries risk and implementing preventive strategies are critical elements of pediatric care, particularly for preschoolers and children with special

c) health care needs.

d) Parents and caregivers must be given the means to mitigate the child's caries risk through effective self-care and healthy lifestyle choices, and by working with dental teams to verify whether the risk management regimen has been effective.

e) It is only through the combined efforts of dental professionals and parents/caregivers that oral disease can be prevented.

\section{References}

1. Farsi NJ, El Housseiny AA, Farsi DJ, Farsi NM (2017) Validation of the Arabic version of the early childhood oral health impact scale (ECOHIS). BMC Oral Health 17(1): 60.

2. (2017) Peel Public Health. Oral Health in Peel: A Taste of Risk Factors and Oral Health Outcomes. 
3. Legg A (2016) Oral health care for children - a call for action. Canadian Pediatric Society 18(1): 37-43.

4. Anil S, Anand PS (2017) Early childhood caries: prevalence, risk factors, and prevention. Frontiers in pediatrics 5: 157

5. (2013) Treatment of Preventable Dental Cavities in Preschoolers: A Focus on Day Surgery under General Anesthesia. Canadian Institute for Health Information Ottawa, USA

6. Leong PM, Gussy MG, Barrow SL, De Silva Sanigorski A, Waters E (2012) A systematic review of risk factors during first year of life for early childhood caries. International Journal of Paediatric Dentistry 23: 235250.

7. De Abreu da Silva Bastos V, Freitas FLB, Fidalgo TK, Martins C, Mattos CT, et al. (2015) Mother-to-child transmission of Streptococcus mutans: A systematic review and meta-analysis. Journal of Dentistry 43(2): 181191.
8. Themessi Huber M, Freeman R, Humphris G, acGillivray S, Terzi N (2010) Empirical evidence of the relationship between parental and child dental fear: A structured review and meta-analysis. International Journal of Paediatric Dentistry 20: 83-101.

9. Hooley M, Skouteris H, Boganin C, Satur J, Kilpatrick N (2012) Parental influence and the development of dental caries in children aged 0-6 years: A systematic review. Journal of Dentistry 40: 873-885.

10. Fisher Owens, Gansky SA, Platt LJ, Weintraub JA, Soobader MJ, et al. (2007) Influences on Children's Oral Health: A Conceptual Model. Pediatrics 120 (3): 510-520.

11. Kumar S, Tadakamadla J, Kroon J, Johnson NW (2016) Impact of parent related factors on dental caries in the permanent dentition of 6-12-yearold children: A systematic review. Journal of Dentistry 46: 1-11.

12. Berg JH, Stapleton FB (2012) Physician and dentist: new initiatives to jointly mitigate early childhood oral disease. Clin Pediatr (Phila) 51: 531-537.

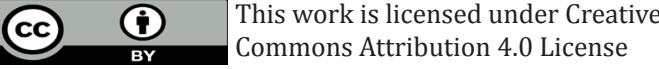

To Submit Your Article Click Here:

Submit Article

DOI: $10.32474 /$ IPDOAJ.2019.02.000149

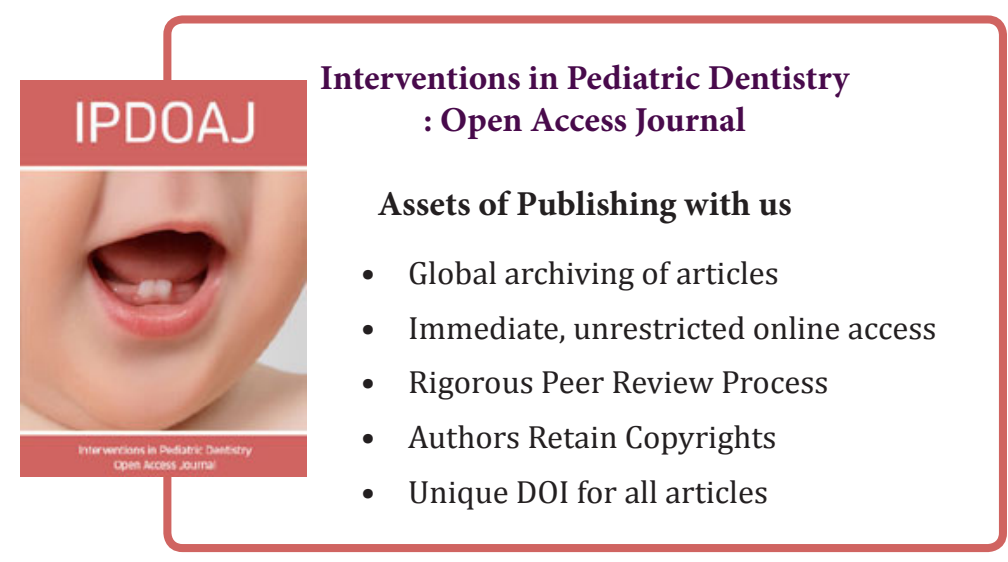

